Bangladesh Journal of Neuroscience 2008; Vol. 24 (1) : 45-49

\title{
Blood Pressure Profile in Post-Stroke Patients
}

\author{
SEHELLY JAHAN ${ }^{1}$, MD TAREK ALAM $^{2}$, ZAFOR MD MASUD $^{3}$, ZAHED ALI $^{4}$
}

\begin{abstract}
Blood pressure profile after ischemic stroke in both hypertensive and non-hypertensive patients usually follows a benign course. This prospective study was done among the admitted patients in Bangladesh medical college, starting from November 2006 to August 2007. We observed 80 cases where there was sharp rise of blood pressure in most cases in the early part of ischemic stroke which gradually came down to its previous level within 7-10 days, without any antihypertensive drug. These patients were specially selected as they had only ischemic stroke with or without hypertension. Patients having comorbidities other than diabetes were excluded.
\end{abstract}

\section{Introduction}

In ischaemic stroke intracranial vessels may be acutely obstructed by many ways leading to tissue damage. Signs and symptoms of neurological deficit depend upon timed restoration of blood supply. If cerebral blood flow is zero, tissue death occurs within 4-10 minute. Values $<16-18$ $\mathrm{ml} / 100$ gram brain tissue per minute cause infarction within an hour and values $<20 \mathrm{ml} /$ minute /100 gram of tissue cause ischemia without infarction unless prolonged. Tissue surrounding the core regions of infarction is called ischemic penumbra. Function of this area is reversible if blood flow can be re-established before it is too late. This ischemic penumbra is the goal of revascularization therapy. As blood flow in the ischemic penumbra is dependent upon blood pressure, sudden fall of blood pressure may be disastrous, and may lead to increment of size of the original infarction. Although we have to reduce blood pressure in case of malignant hypertension, nephropathy, ischemic heart disease, hypertensive encephalopathy etc. without any controversy, but patients having no such complications, whether to reduce blood pressure acutely or not yet remains controversial.

\section{Materials and Methods:}

Inclusion Criteria

Patients with diagnosed ischemic stroke who presented on the $1^{\text {st }}$ day and were conscious was included in this study. No age or sex were exempted. Both hypertensive and non-hypertensive patients were included with or without diabetes.

\section{Exclusion Criteria}

Patients with haemorrhagic stroke were excluded. Patients having ischemic stroke but also suffering from IHD, nephropathy, hypertensive encephalopathy were excluded. Patients with clinical or radiological evidence of raised intracranial

1. Associate Professor of Neurology, Bangladesh Medical College, Dhaka.

2. Assistant Professor of Medicine, Bangladesh Medical College, Dhaka.

3. Assistant Professor of Oncology, Bangladesh Medical College, Dhaka.

4. Assistant Professor of Neurology, Sir Salimullah Medical College, Dhaka. 
pressure were not included in this study.

\section{Methods Used}

It was a prospective study done among the admitted patients in Bangladesh Medical College Hospital starting from November 2006 to August 2007. Patients were carefully selected on the basis of clinical examination and investigation reports who met the inclusion criteria. We took the blood pressure measurements every four hours in first two days then 6 hourly in next two days and finally every 8 hours in last 3 days. Any patient developing any exclusion criteria during this period were excluded from this study and treated accordingly.

\section{Observation and Results}

A total of 82 patients were included in this study but 80 patients completed the whole period. In this study 41 patients were hypertensive and 39 patients were nonhypertensive. Highest systolic blood pressure recorded was 210 and diastolic blood pressure was 110 in hypertensive group and highest systolic blood pressure was 170 and diastolic blood pressure was 100 in non-hypertensive group.

Table-I

Demographic characteristics of the patients $(n=80)$

\begin{tabular}{|c|c|c|}
\hline Variables & Number & Percentage \\
\hline \multicolumn{3}{|l|}{ Sex } \\
\hline Male & 50 & $62.5 \%$ \\
\hline Female & 30 & $37.5 \%$ \\
\hline \multicolumn{3}{|l|}{ Age } \\
\hline$>50$ & 48 & $60 \%$ \\
\hline$<50$ & 32 & $40 \%$ \\
\hline \multicolumn{3}{|l|}{ Blood Pressure } \\
\hline Hypertensive & 41 & $51.25 \%$ \\
\hline Non-hypertensive & 39 & \\
\hline \multicolumn{3}{|l|}{ Glycemic status } \\
\hline Non-diabetic & 50 & \\
\hline Diabetic & 30 & $37.5 \%$ \\
\hline
\end{tabular}

Table-II

Level of systolic blood pressure in hyertensive patients $(n=41)$

\begin{tabular}{lccccccc}
\hline Systolic & $\mathrm{D}-1$ & $\mathrm{D}-2$ & $\mathrm{D}-3$ & $\mathrm{D}-4$ & $\mathrm{D}-5$ & $\mathrm{D}-6$ & $\mathrm{D}-7$ \\
B.P. & $\mathrm{n}(\%)$ & $\mathrm{n}(\%)$ & $\mathrm{n}(\%)$ & $\mathrm{n}(\%)$ & $\mathrm{n}(\%)$ & $\mathrm{n}(\%)$ & $\mathrm{n}(\%)$ \\
\hline $201-210$ & $2(5.13)$ & $1(2.56)$ & & & & & \\
$191-200$ & $3(7.69)$ & $4(10.26)$ & $3(7.69)$ & $3(7.69)$ & & & \\
$181-190$ & $3(7.69)$ & $3(7.69)$ & $3(7.69)$ & $3(7.69)$ & $4(10.26)$ & $2(5.13)$ & $3(7.69)$ \\
$171-180$ & $10(25.64)$ & $3(7.69)$ & $3(7.69)$ & $6(15.38)$ & $3(7.69)$ & $3(7.69)$ & $3(7.69)$ \\
$161-170$ & $12(30.77)$ & $15(38.46)$ & $9(23.08)$ & $4(10.26)$ & $6(15.38)$ & $10(25.64)$ & $15(38.46)$ \\
$151-160$ & $11(28.21)$ & $15(38.46)$ & $23(58.97)$ & $25(64.1)$ & $28(71.79)$ & $26(66.67)$ & $20(51.28)$ \\
\hline
\end{tabular}


Table-III

Level of diastolic blood pressure in hypertensive patients $(n=41)$

\begin{tabular}{lccccccc}
\hline Diastolic & $\mathrm{D}-1$ & $\mathrm{D}-2$ & $\mathrm{D}-3$ & $\mathrm{D}-4$ & $\mathrm{D}-5$ & $\mathrm{D}-6$ & $\mathrm{D}-7$ \\
$\mathrm{BP}$ & $\mathrm{n}(\%)$ & $\mathrm{n}(\%)$ & $\mathrm{n}(\%)$ & $\mathrm{n}(\%)$ & $\mathrm{n}(\%)$ & $\mathrm{n}(\%)$ & $\mathrm{n}(\%)$ \\
\hline $90-100$ & $36(87.8)$ & $35(85.37)$ & $35(85.37)$ & $37(90.24)$ & $38(92.68)$ & $41(100)$ & $37(90.24)$ \\
$101-110$ & $5(12.2)$ & $6(14.63)$ & $6(14.63)$ & $4(9.75)$ & $3(7.32)$ & 0 & $4(9.75)$ \\
\hline
\end{tabular}

Table-III

Level of systolic blood pressure in non-hypertensive patients $(n=39)$

\begin{tabular}{lccccccc}
\hline Systolic & $\mathrm{D}-1$ & $\mathrm{D}-2$ & $\mathrm{D}-3$ & $\mathrm{D}-4$ & $\mathrm{D}-5$ & $\mathrm{D}-6$ & $\mathrm{D}-7)$ \\
BP & $\mathrm{n}(\%)$ & $\mathrm{n}(\%$ & $\mathrm{n}(\%)$ & $\mathrm{n}(\%$ & $\mathrm{n}(\%)$ & $\mathrm{n}(\%)$ & $\mathrm{n}(\%)$ \\
\hline $121-130$ & $12(30.77)$ & $19(48.72)$ & $19(48.72)$ & $25(64.1)$ & $18(46.15)$ & $22(56.4)$ & $32(82.05)$ \\
$131-140$ & $1(2.56)$ & $1(2.56)$ & $1(2.56)$ & $2(5.13)$ & $3(7.69)$ & & \\
$141-150$ & $16(41.03)$ & $13(33.33)$ & $14(35.9)$ & $10(25.64)$ & $18(46.15)$ & $17(43.59)$ & $7(17.95)$ \\
$151-160$ & $7(17.95)$ & $6(15.38)$ & $5(12.82)$ & $2(5.13)$ & & & \\
$161-170$ & $3(7.69)$ & & & & & & \\
\hline
\end{tabular}

Table-IV

Level of diastolic blood pressure in non-hypertensive patients ( $n=39)$

\begin{tabular}{lccccccc}
\hline Diastolic & $\mathrm{D}-1$ & $\mathrm{D}-2$ & $\mathrm{D}-3$ & $\mathrm{D}-4$ & $\mathrm{D}-5$ & $\mathrm{D}-6$ & $\mathrm{D}-7$ \\
$\mathrm{BP}$ & $\mathrm{n}(\%)$ & $\mathrm{n}(\%)$ & $\mathrm{n}(\%)$ & $\mathrm{n}(\%)$ & $\mathrm{n}(\%)$ & $\mathrm{n}(\%)$ & $\mathrm{n}(\%)$ \\
\hline $70-79$ & $5(12.82)$ & $4(10.26)$ & $6(15.38)$ & $9(23.08)$ & $14(35.9)$ & $19(48.72)$ & $28971.79)$ \\
$80-85$ & $18(46.5)$ & $19(48.72)$ & $17(43.59)$ & $15(38.46)$ & $14(35.9)$ & $11(28.4)$ & $8(20.51)$ \\
$86-90$ & $10(25.64)$ & $10(25.64)$ & $10(25.64)$ & $10(25.64)$ & $8(20.51)$ & $6(15.38)$ & $3(7.69)$ \\
$91-95$ & $2(5.13)$ & $4(10.26)$ & $4(10.26)$ & $3(7.69)$ & $1(2.56)$ & $3(7.69)$ & \\
$96-100$ & $4(10.26)$ & $2(5.13)$ & $2(5.13)$ & $2(5.13)$ & $2(5.13)$ & & \\
\hline
\end{tabular}

\section{Discussion}

Management of blood pressure in acute stroke patients varies with the type of stroke and co-morbidities. In ischemic stroke perfusion pressure in vessels distal to the obstruction is low and the vessels become dilated. Blood flow in these dilated vessels is thought to be dependent upon systemic blood pressure.
The mean arterial blood pressure (MAP) is usually elevated in patients with an acute stroke. This may be due to chronic hypertension, which is a major risk factor for ischemic stroke, or to an acute sympathetic response. In many cases, however, the acutely elevated blood pressure is necessary to maintain brain perfusion. A neuroimaging study with $\mathrm{CT}$ or 
MRI is critical to help guide blood pressure therapy in stroke patients.

The observation is that the blood pressure frequently rises spontaneously following cerebral ischemia is consistent with this protective hypothesis, although a stress response to the acute event and to hospitalization may also contribute. The hypertensive effect is transient, as the blood pressure falls by as much as $20 / 10 \mathrm{mmHg}$ within 10 days.

An analysis from the International Stroke Trial of 17,398 patients with an ischemic stroke noted a U-shaped relationship between baseline systolic blood pressure and outcome. Elevated systolic blood pressure was associated with an increased risk of recurrent ischemic stroke (50 percent greater risk of recurrence with a systolic blood pressure of $>200 \mathrm{mmHg}$ versus $130 \mathrm{mmHg}$ ), while low blood pressure (particularly $<120 \mathrm{mmHg}$ ) was associated with an excess number of deaths from coronary heart disease.

A subsequent analysis of 1004 patients with acute ischemic stroke from Okinawa also found a U-shaped relationship between admission blood pressure and death within 30 days after stroke onset ${ }^{3}$. The $U$-shaped relationship was shifted towards higher pressure in patients who had previous hypertension compared with those who did not have previous hypertension. This finding mirrors the shift seen in cerebral autoregulation that occurs in long standing hypertension ${ }^{4}$.

Interventions - Lowering the systemic blood pressure has been associated with clinical deterioration in patients with acute ischemic stroke ${ }^{5-7}$. Observational studies from three different groups have demonstrated an important adverse effect of reducing blood pressure in the first 24 hours after stroke onset ${ }^{6,8,9}$. Odds ratios of poor outcome were similar in the first two studies: 1.9 per 10 percent systolic blood pressure reduction $(95 \% \mathrm{Cl}, 1.02-$ 3.52) in a Brazilian study ${ }^{6}$ and 3.8 for a greater than 25 percent diastolic blood pressure reduction $(95 \% \mathrm{Cl}, 1.2-12.1)$ in an Austrian study ${ }^{7}$. In a Spanish study, a fall in systolic blood pressure $>20 \mathrm{mmHg}$ in the first day was the most important variable associated with neurologic deterioration and poor outcome.

Recommendations - Most consensus guidelines recommend that blood pressure not be treated in the patient with acute ischemic stroke unless the hypertension is extreme (systolic BP $>220 \mathrm{mmHg}$ or diastolic BP $>120 \mathrm{mmHg}$ ), or the patient has active ischemic coronary heart disease, heart failure, or aortic dissection ${ }^{5,10-12}$. When treatment is indicated, cautious lowering of blood pressure by approximately 15 percent during the first 24 hours after stroke onset is suggested ${ }^{10}$.

Blood pressure management in acute stroke remains controversial. Guidelines from the American Heart Association/ American Stroke Association published in 2007 suggested that antihypertensive medications should be restarted at approximately 24 hours after stroke onset in patients with preexisting hypertension who are neurologically stable, unless a specific contraindication to restarting treatment is known.

However, patients with extracranial or intracranial stenosis may require a slower reduction in blood pressure (e.g., over seven to ten days after ischemic stroke), as some degree of blood pressure elevation may be necessary to maintain cerebral blood flow to ischemic brain regions. Special considerations apply to blood pressure 
control in patients with ischemic stroke who are eligible for thrombolytic therapy. Treatment is recommended so that systolic blood pressure is $\leq 185 \mathrm{mmHg}$ and diastolic blood pressure is $<110 \mathrm{mmHg}$ before lytic therapy is started ${ }^{10}$. The blood pressure should be stabilized and maintained below 180/105 $\mathrm{mmHg}$ for at least 24 hours after intravenous rTPA treatment.

\section{Conclusion}

Blood pressure management in acute stroke patients is an unresolved issue. Guidelines from the American Heart Association/American Stroke Association published in 2007 suggest that antihypertensive medications should be restarted at approximately 24 hours after stroke onset in patients with preexisting hypertension who are neurologically stable, unless a specific contraindication to restarting treatment is known ${ }^{1}$. So it is yet to be decided.

\section{References:}

1. Wallace L, Levy L. Blood pressure after stroke. JAMA 1981; 246: 217780.

2. Leonardi-Bee J, Bath PM, Phillips SJ, Sandercock PA. Blood pressure and clinical outcomes in the International Stroke Trial. Stroke 2002; 33: 1315.

3. Okumura K, Ohyad Y, Maehara A. Effects of blood pressure levels on case fatality after acute stroke. J Hypertens 2005; 23: 1217.

4. Bath PM. How to manage blood pressure in acute stroke? J Hypertens 2005; 23:1135.

5. Lavin P. Management of hypertension in patients with acute stroke. Arch Intern Med 1986; 146: 66.

6. Oliveira-Filho J, Silva SC, Trabuco CC. Detrimental effect of blood pressure reduction in the first 24 hours of acute stroke onset. Neurology 2003; 61: 1047.

7. Johnston KC, Mayeri SA. Blood pressure reduction in ischemic stroke: A two-edged sword? Neurology 2003; 61: 1030.

8. Vlcek M, Schillinger M, Lang MW. Association between course of blood pressure within the first 24 hours and functional recovery after acute ischemic stroke. Ann Emerg Med 2003; 42: 619.

9. Castillo J, Leira R, Garcia MM. Blood pressure decrease during the acute phase of ischemic stroke is associated with brain injury and poor stroke outcome. Stroke 2004; 35: 520.

10. Adams HP Jr, del Zoppo G, Alberty MJ. Guidelines for the early management of adults with ischemic stroke: a guideline from the American Heart Association/American Stroke Association Stroke Council, Clinical Cardiology Council, Cardiovascular Radiology and Intervention Council, and the Atherosclerotic Peripheral Vascular Disease and Quality of Care Outcomes in Research Interdisciplinary Working Groups: the American Academy of Neurology affirms the value of this guideline as an educational tool for neurologists. Stroke 2007; 38: 1655.

11. Phillips SJ, Whisnant JP. On behalf of the National High Blood Pressure Education Program: Hypertension and the brain. Arch Intern Med 1992; 152:938.

12. Ringleb PA, Bertram $M$, Keller $E$, Hacke W. Hypertension in patients with cerebrovascular accident. To treat or not to treat? Nephrol Dial Transplant 1998; 13: 2179 